\title{
Entrevista con Ángel Facio, director de teatro ${ }^{1}$
}

\author{
Por María Bastianes \\ (ITEM - Universidad Complutense de Madrid)
}

1. Según tengo entendido, los orígenes de su puesta en escena de la obra de Rojas se remontan a 1977, cuando lo invitan a realizar un montaje en la Real Escuela Superior de Arte Dramático (RESAD). ¿Por qué escoge trabajar con La Celestina?

Creo que La Celestina es uno de los grandes textos de la literatura dramática mundial. A mí me dijeron que si no fuera por Don Quijote, La Celestina sería nuestro mayor texto. Y para mí es un texto dramático, aunque impuro. En la RESAD yo quería ver todo el proceso de elaboración de un montaje, desde la primera lectura hasta la puesta en escena y la obra de Rojas me parecía una opción perfecta para trabajar durante un curso entero. Luego haría lo mismo en la Escuela Superior de Arte Dramático de Murcia con Fuente Ovejuna. Es decir, escoger un texto y, durante los nueve meses del curso, trabajar a fondo con él.

2. Desde la experiencia de haber trabajado con el texto, ¿cree que $L a$ Celestina es obra de uno o de varios autores?

Yo creo que es de un único autor, pero esa es un discusión del ámbito académico que para mi trabajo no resulta importante.

3. El montaje se estrenó en 1979 en Colombia. ¿Cómo se llevó la obra a este país?, ¿cómo escogió a los actores?

En la RESAD la idea inicial había sido pasar por el proceso completo de creación hasta montarla, pero por falta de dinero solo pudimos trabajar

1.- Esta entrevista fue realizada en agosto de 2014 en casa de Ángel Facio. El presente trabajo se ha beneficiado de mi vinculación a los proyectos "TEAMAD-CM. Plataforma digital para la investigación y divulgación del teatro contemporáneo en Madrid», financiado por la Comunidad Autónoma de Madrid (código: H2015/HUM-3366), y «PTCE. Primer Teatro Clásico Español. Plataforma para la investigación textual y escénica del Teatro Español del XVI (1496-1542)» del Plan Nacional de Investigación «Excelencia», otorgado por el Ministerio de Economía y Competitividad (código: FF12015-64799-2016-2019). 
la elaboración de una dramaturgia a partir del texto. Finalmente estrené la versión en Colombia. El Ministerio de Cultura de Colombia (Colcultura) quería restar poder a la Corporación Colombiana de Teatro y montar una compañía nacional de teatro. Hicimos unas audiciones y vino gente de todo el país. En todo momento intenté explicar que La Celestina es un clásico tanto de España como de Latinoamérica: hasta la independencia toda nuestra cultura es común y la lengua de los clásicos resulta para el espectador actual igual de extraña aquí que allí. Es más, hay frases y palabras del texto que aquí no se entienden y allí sí. En Colombia encontré dos actores espléndidos para hacer de Celestina y finalmente escogí a uno de ellos, Mario Ceballos.

4. ¿Por qué eligió a un hombre para interpretar al personaje de Celestina en Colombia y, por el contrario, abandonó este recurso al traer la obra a España?

Cuando hice las pruebas en Madrid no encontré un actor de edad, consistencia y entidad suficientes; si no hubiera sido un hombre también. A mí me daba igual. En realidad, me interesaba la ambigüedad del personaje, si hubiese podido omitir el nombre del actor que encarnaba a Celestina en los programas de mano lo habría hecho.

5. Tengo entendido que en Colombia hubo algunos problemas con los organizadores (Colcultura), ¿qué sucedió exactamente?

Les molestó que Calisto y Melibea aparecieran desnudos. Tuvo que venir a un ensayo la secretaria de cultura y decir que no pasaba nada. Los desnudos causaron revuelo, el montaje salió incluso en la portada de una revista del corazón (Cromos).

6. ¿En Colombia se monta el mismo espectáculo que se vio luego en España?

Sí, exactamente el mismo.

7. En el apartado introductorio "Razones para una versión» de la edición del texto de su versión se mencionan las puestas en escena anteriores de Tamayo, Manzaneque, Bilbatúa. ¿'Tuvo en cuenta montajes previos de la obra, españoles o latinoamericanos, a la hora de realizar su propia versión escénica? ${ }^{2}$

Conocía anteriores puestas en escenas españolas, pero no latinoamericanas. Yo quise hacer algo diferente. Por ejemplo, le di muchas vueltas a la escena de la muerte, casi siempre resuelta de manera muy ridícula y poco creíble (en todos los montajes previos que había visto Melibea y Ca-

2.- Facio, Ángel (1984): La Celestina, Madrid, Círculo de Bellas Artes, 27. 
listo caían con mucho aspaviento desde una altura de solo tres metros). Se me ocurrió entonces que tenían que caer hacia arriba. Mediante polipastos los cuerpos quedaban colgados boca abajo, desnudos, a once metros de altura. En ese momento del espectáculo el público se quedaba sin respiración, una reacción que me confirmaba que el recurso funcionaba.

\section{8. ¿Un adaptador tiene completa libertad para trabajar con un clásico?}

Una vez tuve una discusión sobre mi versión de La Celestina con un catedrático. No era celestinista, pero empezó a invocar un montón de citas. Yo me había leído todo lo que llegaba a España sobre la obra y le dije que lo que escribió Fernando de Rojas era un texto que no se podía montar sin modificaciones simplemente porque el autor no estaba escribiendo para un teatro, sino para una lectura en voz alta delante de un público de colegas. En la época no había locales ni espacios específicos para representar. Sin embargo, La Celestina es una obra de gran contenido dramático, por eso se han hecho tantas versiones escénicas, aunque siempre modifica do el original. No se puede juzgar una versión de la obra de Rojas como se juzgan las adaptaciones de Lope de Vega o Tirso de Molina, a los que no se les puede tocar una coma (cosa que también me parece una barbaridad). Cuando se trabaja con un texto como La Celestina hay que cambiar poquita cosa y mantener el sentido, pero para eso hay que escribir lo mismo de otra manera. El teatro está hecho para el público, no para los catedráticos, ¿acaso hay alguien que estuviese en el cuerpo de Fernando de Rojas para saber lo que pensaba? Además, las obras que escriben los autores son patrimonio de la sociedad que los ha criado, es ridículo plantear una fidelidad al texto. El texto sigue ahí, nosotros no vamos a falsificar nada: quien quiera leer el original puede hacerlo.

El problema es que los académicos siempre han tenido la idea de que somos unos incultos y unos bárbaros. Y es verdad que a muchos profesionales del ámbito del teatro - a gente como Tamayo- no les importaba estudiar e informarse sobre la obra, pero no somos todos así. Yo soy licenciado en Ciencias Políticas, trabajé catorce años como profesor y cuando me enfrento a un clásico tengo mis armas bien afiladas.

9. En la versión que usted realizó se mantenía la trama pero se reordenaban los diálogos. ¿Por qué se trasladaban los parlamentos de un personaje a otro/s?

El procedimiento fue muy curioso, un trabajo de tipo casi universitario. Lo primero que hice fue dividir por relaciones: relación Calisto-Melibea, Celestina-Sempronio, Celestina-Elicia, etc. Luego tuve en cuenta elementos descriptivos (el laboratorio de Celestina), filosófico (la vejez, la juventud), etc. Y así diseccioné todo el texto. Es como si cogiese un cuadro clásico, recortarse por líneas y colores, y luego volviese a componer el 
mismo cuadro cuatro veces más pequeño. Hay parlamentos que da igual quién los diga porque no tienen absoluta relación con el personaje. Así sucedía, por ejemplo, con los muchos refranes y dichos cogidos de la sabiduría popular.

10. ¿Por qué desaparecían del montaje personajes como los padres de Melibea?

En La Celestina hay varias historias y uno debe elegir cuál contar. Yo quise centrarme en la relación entre Calisto, Melibea y Celestina, que era lo más importante de la obra para mí. De esta manera, opté por mostrar tres espacios fundamentales: las casas de estos tres personajes. La historia de los padres, por el contrario, me parecía que estaba al margen, aunque lamenté no incluir el planto de Pleberio. El planto tiene frases maravillosas, algunas las reintroduje en otros pasajes de la versión.

En definitiva, mi versión se organizaba de la siguiente manera: primero tenía lugar la perversión de los criados por parte de Celestina, luego los criados ayudaban a que Calisto y Melibea se encontraran y, finalmente, el azar y la propia idiotez de Calisto (un gilipollas perdido, a diferencia de Melibea que no es nada tonta) causaban su muerte. Por último, se mostraba el suicidio de Melibea, que después de haber probado el «soberano deleyte» ya no encuentra sentido a seguir viva sin su amante.

11. Las relaciones del mundo de los criados se simplificaban, ¿por qué las prostitutas Elicia y Areúsa se transformaban en su montaje en criadas?

Para guardar la simetría. Me parece que la simetría es importante en esa visión renacentista. Además, el cambio era conveniente para el lenguaje ritual empleado en la versión.

12. ¿Cree que el texto de Rojas ofrecía un modelo de clásico de alguna manera "alternativo» en aquellos años setenta en que los clásicos barrocos se miraban con desconfianza?

Da igual trabajar con un texto barroco o prebarroco mientras tenga entidad, posea calidad, y el tema siga siendo universal. La vida es sueño, Fuente Ovejuna o La Celestina son tan ricos que los cojas por donde los cojas... En definitiva, la elección de La Celestina no fue una cuestión de moda o antimoda. La Celestina es un texto distinto evidentemente. Es el único que en ese sentido es "anticlásico». No es que sea una alternativa a los clásicos barrocos, yo creo que es mucho más libre que los textos encorsetados del xvil, pero también más difícil porque es más impuro. En las obras de Lope de Vega o Pedro Calderón de la Barca la fórmula dramática es cerrada, es perfecta, es exacta, mientras que en La Celestina es completamente abierta. Es un texto "predramático», donde se mezclan 
elementos novelescos y dramáticos porque todavía no están perfilados los géneros. Esa es la razón por la que no se puede representar entero, se le deben quitar los elementos farragosos que lastran la acción principal, como la descripción que hace Pármeno del laboratorio de Celestina. En el Círculo de Bellas Artes grabamos una lectura completa y duró nueve horas y media. Nueve horas y media no hay quien las soporte.

Ahora bien, cuando hago La Celestina creo ser fiel a Rojas, cuando hago Calderón creo ser realmente infiel a Calderón. A Calderón lo «traiciono» en lo que quiere decir, a Rojas no. La Celestina es una obra, en cuanto a ideas, mucho más «liberal», por así decir, que las del Barroco. Maravall, que fue mi profesor, tenía muy claro que el mundo social de La Celestina es otro. Se trata de una sociedad más abierta, con importantes elementos judaicos y árabes además (algo árabe hay en la misma figura de Celestina). El Renacimiento fue una época de libertad, un mundo donde se ha eliminado el corsé medieval y todavía no se ha impuesto el corsé barroco. Fue una época de libertad que luego fue reprimida y encauzada de otra manera. Yo creo que La Celestina es la obra más blasfema de la literatura universal. Es una barbaridad todos los planteamientos contra Dios, contra el Uno.

13. Su versión escénica enfatizaba la división entre mundo de criados y mundo de señores, ¿̨por qué razón?

A lo largo de la obra de Rojas Celestina emplea diversas estrategias para seducir a los criados y prostitutas en distintos momentos. En la versión quise reunir estos momentos dispersos en el cuadro tres, centrado en la corrupción de los criados, con el fin de destacar el pacto entre estos y Celestina para medrar a costa de los señores. Se trata de una ruptura de las relaciones señoriales preexistentes y de los vínculos de fidelidad medievales. Realmente es un discurso de clase, un «uníos contra ellos».

\section{4. ¿Cómo mostraba este «conflicto de clases» mediante la disposición escénica?}

Cuando terminé de seleccionar los segmentos de la obra original que debían formar parte de la versión armé los distintos cuadros: primer cuadro, el encuentro; segundo cuadro, la investidura (los criados visten a los amantes, les colocan en un lugar social); tercer cuadro, la corrupción de los criados, etc. El de la investidura era uno de los cuadros más difíciles, a veces salía muy mal y cuando salía muy mal no se entendía nada. Mientras eran vestidos por los criados, Calisto y Melibea, cada uno por su lado, hablaban de sus amores como si se hubiesen conocido en otra galaxia. Una vez vestidos, los criados, mediante unas poleas, izaban a los señores a su espacio en lo alto de las torres. En este sitio había un banco para sentarse y una jaula con unas palomas (los amantes luego las solta- 
ban antes del encuentro amoroso). El cuadro siguiente, el de la corrupción de los criados, empezaba con la presentación de Celestina. Primero todos le temían, pero luego lograba sacar a los criados de sus cubículos con promesas. Por último, la imagen final de los criados y la alcahueta remitía a un motivo muy frecuente en la época: los devotos al amparo de un santo patrón. A partir del momento en que Celestina convencía a los criados, la acción seguía más de cerca el orden de la trama original. Los criados colocaban las escaleras en cruz de manera que la alcahueta pudiera subir a hablar con Calisto y Melibea. Luego, mediante una olla de barro a la que se le echaba incienso para que hiciera humo, se escenificaba la invocación al diablo y el conjuro en el cruce de las dos escaleras. Más tarde tenían lugar las visitas a casa de Calisto y Melibea, el encuentro entre los amantes con las escaleras en horizontal, etc. Los criados eran los encargados de ir cambiando la disposición de las escaleras y la escenografía siguiendo las órdenes de Celestina. Estaban constantemente en escena y cuando no eran el foco de atención tenían que realizar acciones paralelas: una se despiojaba, otra se lavaba las piernas, a veces dormían...

Otro aspecto importante para marcar esta diferencia de clases es el de la comida. Calisto y Melibea no comen, y los criados siempre están hablando de comida, siempre están deseando... En mi propuesta había en cada una de las torres de la escenografía unas cubas con rendijas que representaban las despensas. Cuando los criados celebraban el éxito de la empresa asaltaban estas despensas, comían y se entregaban al placer carnal. Calisto y Melibea, con eso del amor, no comen, son etéreos, mientras que los otros viven en la necesidad.

15. Es decir, también se marcaba una división entre amores de señores y amores de criados...

Los amores de los criados son más reales, más apegados a sus necesidades diarias, a diferencia de los de los señores. Sempronio cuando escucha a Calisto se muere de risa, aunque él dice hacer lo mismo con su Elicia. Y Pármeno quiere a Areúsa, lo que Celestina utiliza para comprarlo. Las relaciones que unen a los personajes bajos, su propia manera de expresarse, son más vulgares. Son muy diferentes a la exquisitez cortesana que caracteriza a los amores de Calisto y Melibea.

\section{6. ¿Cuál es la idea detrás del impactante comienzo de su montaje?}

El primer cuadro me lo inventé, en el original el primer diálogo de los amantes ocupa solo unas pocas líneas. Al comenzar la función Calisto y Melibea aparecían tendidos en el suelo y con los ojos tapados con un paño. Mientras sonaba de fondo un canto gregoriano empezaban a gatear, se tocaban, se asustaban, se reconocían. Este momento lo planteé como si fuese el encuentro del primer hombre con la primera mujer en el paraíso 
terrenal. Un estado ideal, como el buen salvaje de Rousseau. En un momento los actores se quitaban las vendas mutuamente; pero cuando iban a abrazarse caía del telar una espada de dos metros. Esta imagen remitía al motivo medieval de los amantes separados por la espada, símbolo de castidad. Era bastante impresionante, los espectadores daban un bote en la butaca. La espada era auténtica, no de cartón piedra. Se sujetaba con hilos de nailon, que tienen cierta elasticidad, de manera que al caer atravesaba el suelo de los escenarios. De hecho, tuvimos que poner un taco de refuerzo en el piso para que se clavara allí. El taco quedaba oculto por la estera de cuerdas de diversos espesores cosidas sobre saco que conformaba el suelo (era todo muy ocre, color madera, natural). Al caer la espada Calisto y Melibea se asustaban y retrocedían. En cada uno de los laterales había tres frailes que los vendaban para evitar el desnudo. Así vestidos se repetía el diálogo inicial, pero esta vez Melibea rechazaba y echaba a Calisto, como en la obra original. Luego, el personaje del Gran Inquisidor decía el incipit. Cuando terminaba esta primera parte los criados vestían a los señores. El acto simbolizaba la entrada en un proceso histórico y la consecuente división entre un arriba y un abajo en la sociedad, ya no se estaba en ese estado previo ahistórico del inicio. La espada descendía otra vez al final de la obra y el ruido provocaba el susto y caída de Calisto. De esta manera, el final enlazaba con el principio de manera circula .

17. Si los montajes franquistas mostraban una lectura moral contra los excesos de la pasión y el sexo, ¿la suya es una lectura de signo opuesto, en contra de la represión moral?

Evidentemente, eso es La Celestina. Si uno la lee con un poco de detenimiento se nota que es el texto más blasfemo de la literatura universal. La obra crítica más completa como análisis de la obra de Rojas es La originalidad artística de "La Celestina» de María Rosa Lida de Malkiel, pero yo creo que Gilman es el celestinista más aventurado. Él ubica el texto en su verdadera dimensión, como obra de un converso, lectura mucho más fructífera, pues permite entender mejor la obra. Creo que La Celestina es la venganza de un resentido. Lo más curioso de todo es que después de escribirla, en lugar de aprovechar el éxito, Rojas no vuelve a publicar nada más. En este sentido es una obra rara. Es curioso también que no se la prohíba hasta finales del siglo xviII.

18. En el montaje aparecía el motivo converso, ¿de qué manera se incluyó en su lectura?

En la escenografía el centro del nido de Celestina era una estrella de David. Se trataba simplemente de una alusión al motivo converso. En la primera edición de la Comedia no aparece ni siquiera el nombre del autor, creo que ese detalle responde al miedo a la Inquisición. Es posible 
que, con el éxito de la obra, Rojas cogiese confianza y decidiese incluir el acróstico en ediciones posteriores. Además, las disculpas que esboza en el prólogo que se añade en la Tragicomedia constituyen también una manera de protegerse. Digamos que Rojas nadaba y guardaba la ropa, lo cual no invalida la brutalidad y atrevimiento del texto.

19. El motivo de la Inquisición fue empleado por Paul Achard en su versión francesa de la obra de Rojas estrenada en 1942, como consecuencia de la reactivación, luego de la Guerra Civil, de una imagen de España como pueblo cruel y sanguinario. El éxito de este montaje pondrá de moda dicho motivo en posteriores puestas en escena de La Celestina en el extranjero (especialmente en Alemania), siempre desde una lectura negra. ¿Cuál es la función que cumple el motivo en su montaje? ${ }^{3}$

No conocía la versión de Achard. Además cuando me puse a trabajar con la obra de Rojas no busqué qué se había hecho antes, no tuve en cuenta ningún material de ese tipo. En mi montaje, el motivo de la Inquisición se utiliza para simbolizar de una forma más clara la represión que vendría después con los Austrias y con el Siglo de Oro ( $L a$ Celestina es de finales del Xv y entonces la Inquisición no era aún lo que sería luego). Por eso decidí mostrar a los inquisidores como frailes, es decir, como eran en un principio y no como los funcionarios en los que se convertirían después, cuando la Inquisición cobrase fuerza. En un inicio eran principalmente frailes dominicos, pero en mi montaje aparecían como franciscanos por razones puramente estéticas: el traje, con la capucha que no dejaba ver la cara, era más bonito y siniestro. Además la capucha permitía ocultar los rostros de los actores, que eran los mismos que luego harían de criados (solo necesitaban quitarse el hábito, llevaban debajo el otro vestuario).

20. La edición de la versión incluye, entre otras, una cita de la Historia de la poesía alemana de Gervinus en la que se establece un paralelismo entre la manera en que se desarrollan los amores de Romeo y Julieta y lo que sucede en la obra de Rojas. ¿Cuál cree que es la relación entre las dos obras? ${ }^{4}$

Creo que Shakespeare leyó a Rojas. Y además, de haber continuado la línea teatral que inicia La Celestina nuestro teatro hubiese llegado a Shakespeare. Hay más unión entre La Celestina y el teatro de Shakespeare, que entre la primera y el teatro barroco.

3.- Véase Rodiek, Christoph (1989): «La Celestina del siglo xx. Anotaciones comparatistas», Celestinesca, 13/2, 39-44.

4.- Facio, op. cit., 24. 
21. Pero en otro apartado de la edición desaconseja la comparación con Romeo y Julieta porque no hay matrimonio...

Ambas son historias de amores frustrados, aunque los personajes sean completamente distintos. Melibea es una doncella aguda, sensible, que reconoce el mundo en que está. Calisto es un gilipollas, es un señorito que se cree que todo lo puede con dinero, un fetichista. En Romeo y Julieta el desencadenante del conflicto es una lucha entre dos familias que no existe en el texto de Rojas: los dos amantes pueden casarse con quienes quieran. Sin embargo, Melibea se encarga de hacernos saber que no quiere marido, solo quiere gozar del «soberano deleyte». En este sentido, La Celestina es mucho más atrevida, después de todo Romeo y Julieta se casan, es decir, aceptan las normas.

Además, los personajes que están detrás de la trama principal en una obra y otra son distintos. En Romeo y Julieta los motores de la tragedia son Paris, Teobaldo, Mercutio y la pelea entre las familias... Son todos personajes altos, muy distintos a la alcahueta y los criados de la obra de Rojas.

22. Un tópico frecuente, sobre todo en los primeros montajes españoles de La Celestina, es la comparación de Celestina con el personaje Mefistófeles del Fausto, usted en cambio nombra el núcleo correspondiente a la escena del conjuro como «Presencia del doctor Fausto».

Para mí Celestina no es Mefistófeles, no es el diablo. Es Fausto, no hay más que echarle un ojo al laboratorio para comprender que Celestina es una fuerza científica y no maléfica, avanzadísima para la época, ademá

23. ¿De qué manera se organizaba la elección de imágenes simbólicas en el montaje?

Una vez que concibes la idea central que rige el diseño de espacio escénico (en este caso las tres casas de Calisto, Melibea y Celestina, y el espacio libre entre ellas), van surgiendo el resto de las imágenes. Te das cuenta de que el suelo no puede ser liso, sino una alfombra de nudos que recuerdan las raíces de los árboles, por ejemplo; o que los amantes deben soltar unas palomas antes de entregarse y perder la virginidad. La casa de Celestina semejaba un nido de una araña, también tejido. Son detalles que vas afinando y que en general se relacionan con la época de la obra de Rojas. He sido profesor catorce años de Historia y en mis montajes la Historia es importante. Un detalle que estaba en el idea original del montaje, pero que luego descarte, era incluir en la parte del ajusticiamiento de los criados un instrumento de tortura que aparece en un cuadro de Berruguete: una especie de chimenea que llevan unos reos en los genitales por sodomitas. Quise colocar también una goma por donde expulsaran el semen de la última eyaculación de los ahorcados, a partir del cual iban a crecer en el suelo unas mandrágoras. Yo pretendía que después Celestina 
diera esta planta afrodisíaca a Calisto y Melibea. Pero al final no incluí ninguna de estas ideas porque en la puesta en escena no se veían bien.

\section{4. ¿Y las torres?}

Las torres me ayudaban gráficamente en el montaje, me resultaban una forma fácil de situar el arriba (lugar de los señores) y el abajo (lugar de los criados). Los criados, seducidos por Celestina, son los que ponen las escaleras para que la alcahueta pueda subir a un lado u a otro.

25. ¿Qué le aportaba la estética ritual a un texto como el de Rojas, tradicionalmente asociado al realismo?

Bueno, no dejaba de ser realista por ser ritual. Un lenguaje ritual escénico permite situar históricamente de manera simbólica. Cambiar los decorados para pasar de casa de Calisto a casa de Melibea o a casa de Celestina es muy pesado. Es decir, es mejor situarlo todo en un mismo lugar, y eso te obliga al ritual y a lo simbólico: casa de Calisto, casa de Melibea, casa de Celestina, y un espacio de libertad en medio. Todos estos espacios se unían a través de Celestina, caracterizada como una gran araña que tiende sus redes. Cuando Celestina aparecía por primera vez en el montaje se levantaba todo un entramado de cuerdas en el fondo que era como su tela de araña.

Todo la escenografía estaba hecha con maderas y redes, las redes eran lo más difícil de manejar porque tenían que tener mucha tensión para que no bajasen al suelo con el peso de los actores, teníamos que anclarlas a las paredes con elementos de presión.

26. ¿Cómo fue la reacción del público?, ¿qué diferencias notó en cada sitio?

Les parecía una cosa muy rara en todos lados, en los sitios donde habían oído hablar de La Celestina gustó más. En España me sentí más cómodo en Madrid; en Barcelona no fue bien porque la función era al aire libre y la humedad estropeaba las cuerdas. En cambio el Círculo de Bellas Artes fue un lugar perfecto para montar la obra. Luego, además, dábamos conferencias en los institutos para animar a la gente.

27. ¿Pudo ver la versión de Ricardo Iniesta del año 2012? El director de Atalaya menciona que su montaje lo impresionó.

No, no la he visto.

28. ¿Qué significó la puesta en escena de La Celestina en su trayectoria como director?

Es el mejor montaje que he hecho, no el mejor espectáculo. El mejor espectáculo dependía de los actores y no era exacto, siempre fallaba al- 
guno; pero como puesta en escena yo creo que es la mejor. Lo malo del montaje cuando se hizo en España es que se adelantaba a la dotación técnica de los teatros de aquel momento. La construcción de la escenografía era muy artesanal, pero necesitaba de un teatro en condiciones: había que anclar las torres al suelo, utilizábamos poleas múltiples y las redes se tensaban fortísimo. Antes de llegar al Círculo de Bellas Artes, durante las giras, estuvimos en teatros que no estaban bien equipados. Llevábamos a un asistente de dirección colombiano, Miguel Durán, que tuvo que luchar contra las pobres condiciones de los espacios.

\section{9. ¿Qué cambiaría si la volviese a hacer?}

De hacerla ahora no sería tan fiel, no tendría tan en cuenta a Rojas. Yo creo que es una obra mía de madurez y por ello no cambiaría nada; pero intentaría hacer inteligibles refranes y frases que hoy no se entienden.

\section{LA CELESTINA (1979-1984)}

ADAPTACIÓN y DIRECCIÓN: Ángel Facio

Compañía: Teatro Colón.

Estreno: marzo de 1979, Teatro Colón (Bogotá).

LUGARES:

1. Bogotá.

Reparto: Mario Ceballos (Celestina), Aura María Rojas (Melibea), Luis Eduardo Arango (Calisto), Lucy Bolaños, Iván Cardozo, Héctor Fabio Cobo, Jairo Florián, Sergio Gómez, Blanca Molina, Iván Montoya, Gloria Ramírez, Alberto Sánchez, Hugo Torregosa.

Resto del equipo: Talleres Asartes (realización de escenografía y vestuario), Manolo Corral (productor ejecutivo), Roberto Salazar (secretaría de dirección). Fuente: Archivo de Ángel Facio.

Compañía: Teatro del Aire.

Estreno: 13 de agosto de 1981, Teatro Grec de Montjuich. LUGARES:

1. Barcelona (Teatro Grec, del 13 al 16 de agosto de 1981), 
Salamanca (Teatro Coliseum, del 21 al 22 de agosto de 1981), San Sebastián (Teatro Astoria, del 26 al 30 de agosto de 1981), Guadalajara (Teatro Luengo, 8 de septiembre de 1981).

Reparto: Ketty Ariel (Celestina), Charo Amador (Melibea), Fernando Romo (Calisto), Paco Menéndez (Sempronio), Daniel Moreno (Pármeno), Lola Casamayor (Elicia), Gloria Villalba (Areúsa), Cristina Vázquez (Lucrecia), David Álvarez (Tristán), José Luis Serrano (Gran Inquisidor).

Resto del equipo: José Hernández (ambientación), Begoña del Valle-Iturriaga (Vestuario), Santiago Herranz (coordinación técnica), Jaro Onsurbe (regiduría de escena), Gloria de Benito (gerencia), Miguel Durán (asistencia de dirección), Ángel Facio (espacio escénico).

Fuente: Archivo de Ángel Facio.

2. Valladolid (Teatro Valladolid, del 28 al 31 de enero de 1982), Murcia (Teatro Romea, del 4 al 7 de febrero de 1982), Washington (George Washington University, del 2 al 4 de marzo de 1982), New York (Hunter College, del 7 al 8 de marzo de 1982), Chicago (University of Illinois, del 12 al 13 de marzo de 1982), Boston (Wellesley College, del 19 al 20 de marzo de 1982).

Reparto: Asunción Sancho (Celestina), Charo Amador (Melibea), Fernando Romo (Calisto), Paco Menéndez (Sempronio), Daniel Moreno (Pármeno), Lola Casamayor (Elicia), Gloria Villalba (Areúsa), Cristina Vázquez (Lucrecia), David Álvarez (Tristán), Santi Ugatz (Gran Inquisidor).

Resto del equipo: Begoña del Valle-Iturriaga (vestuario), Pablo Esteban (jefe técnico), Eduardo Guzmán (regiduría de escena), Santiago Ganuza (gerencia), Miguel Durán (asistencia de dirección), Ángel Facio (espacio escénico). Fuente: Archivo de Ángel Facio.

3. Gira por España 1982-1983: Venta de Baños (Teatro Estación, del 14 al 15 de agosto de 1982), Sevilla (Teatro Lope de Vega, del 2 al 9 de septiembre de 1982), Burgos (Gran Teatro, del 
22 al 23 de septiembre de 1982), Miranda de Ebro (Teatro Cinema, 25 de septiembre de 1982), Olessa de Montserrat (Teatro Olessa, 2 de octubre de 1982), Terrassa (Centro Cultural, 4 de octubre de 1982), Olot (Teatro Principal, del 6 al 7 de octubre de 1982), Molins de Rei (Teatro Juventud, del 11 al 12 de octubre de 1982), Alicante (Teatro Principal, del 15 al 17 de octubre de 1982), Palma de Mallorca (Auditórium de Palma, del 20 al 24 de octubre de 1982), Zaragoza (Teatro Principal, del 27 al 31 de octubre de 1982), La Coruña (Teatro Rosalía de Castro, del 4 al 5 de noviembre de 1982), Bilbao (Teatro Ayala, del 8 al 10 de noviembre de 1982), Baracaldo (Teatro Guridi, del 11 al 13 de noviembre de 1982), Vitoria (Teatro Principal, del 15 al 17 de noviembre de 1982), Tudela (Teatro Gaztambide, 19 de noviembre de 1982), Valladolid (Teatro Zorrilla, del 21 al 23 de noviembre de 1982), Toledo (Teatro Rojas, del 26 al 27 de noviembre de 1982), Villena (Teatro Chapí, 6 de diciembre de 1982), Elda (Teatro Castelar, 26 de enero de 1982), Mérida (Teatro Alcazaba, 1 de marzo de 1982), Badajoz (Teatro López de Ayala, 3 de marzo de 1982), Azuaga (Teatro Capitol, 5 de marzo de 1982), Jaen (Teatro Asuán, 8 de marzo de 1982), Almería (Teatro Cervantes, del 10 al 11 de marzo de 1983), Oviedo (Teatro Campoamor, del 13 al 14 de abril de 1983), El Ferrol (Teatro Joffre, del 16 al 17 de abril de 1983), Pontevedra (Teatro Malvar, 19 de abril de 1983), Santiago (Teatro Principal, del 20 al 21 de abril de 1983), Sevilla (Teatro Álvarez Quintero, del 3 al 9 de mayo de 1983), Carmona (Teatro Cerezo, 11 de mayo de 1983), Puerto Real (Teatro Principal, del 27 al 28 de mayo de 1983), Ecija (Teatro Cabrera, 31 de mayo de 1983).

Reparto: Dora Santacreu (Celestina), Charo Amador (Melibea), Tony Maroño (Calisto), Paco Menéndez (Sempronio), Ernesto Ruiz (Pármeno), Charo Urricelqui (Elicia), Gloria Villalba (Areúsa), Cristina Vázquez (Lucrecia), David Álvarez (Tristán) y Juan Carlos Lavid (Gran Inquisidor). Resto del equipo: Begoña del Valle (vestuario), Elena Ramos (utilería), Pablo Esteban (coordinación técnica), Alicia 
Moreno (programación), Eduardo Guzmán (regiduría de escena), Miguel Durán (asistencia de dirección), Ángel Facio (espacio escénico).

Fuente: Archivo de Ángel Facio.

4. Madrid (Sala Fernando de Rojas del Círculo de Bellas Artes, 16 de octubre a 30 de noviembre de 1984).

Reparto: Dora Santacreu (Celestina), Charo Amador (Melibea), Ángel Pardo (Calisto), Francisco Torres (Sempronio), Ernesto Ruiz (Pármeno), Aurora Herrero (Elicia), Blanco Plaza (Areúsa), Cristina Vázquez (Lucrecia), David Álvarez (Tristán) y Juan Carlos Lavid (Gran Inquisidor).

Resto del equipo: Begoña del Valle (vestuario), Elena Ramos (utilería), Luis Caballero (fotografía), Pablo Elorriaga (carpintería), Victoria (realización vestuario), Miguel Durán (coordinación técnica), Marisol Cobos (prensa e imagen), Pablo Esteban (asistencia de dirección), Ángel Facio (espacio escénico).

Fuente: Archivo de Ángel Facio. 